\title{
Uranus System Exploration Under the New Frontiers Mission Class (A Novel Perspective)
}

Primary Author: Tibor S. Balint JPL/Caltech (626) 658-6569 tibor.balint@jpl.nasa.gov Contributors:

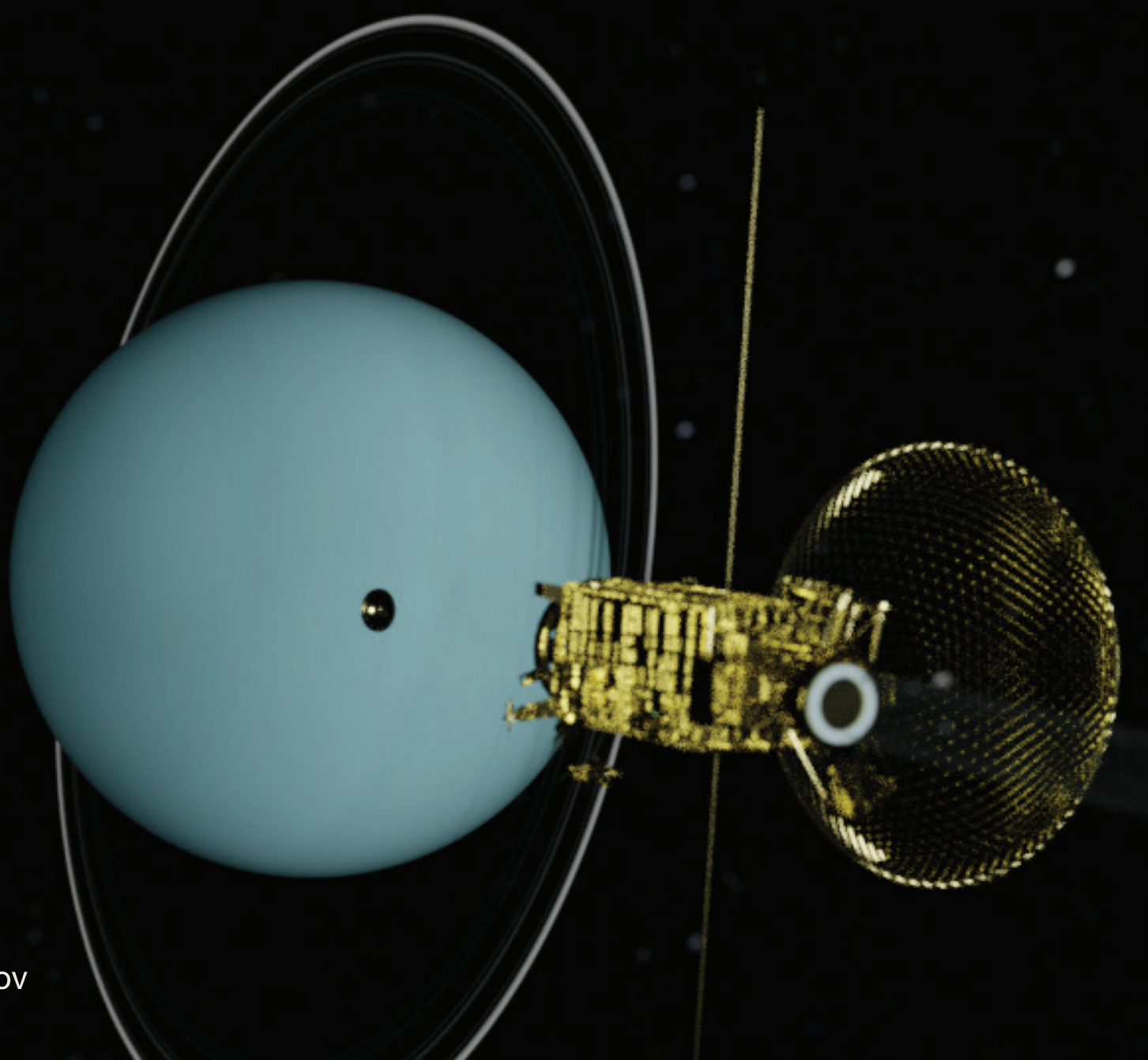

David Atkinson ${ }^{1}$, Alessandra Babuscia ${ }^{1}$, John Baker 1 , Case Bradford ${ }^{1}$, Catherine Elder ${ }^{1}$, Ryan Conversano ${ }^{1}$, Sabrina Feldman ${ }^{1}$, Benjamin Furst ${ }^{1}$, Anthony Freeman ${ }^{1}$, Gregory Garner ${ }^{1}$, Dan Goebel ${ }^{1}$, Sona Hosseini', Erin Leonard ${ }^{1}$, Tom Andre Nordheim ${ }^{1}$, Anastassios Petropoulos ${ }^{1}$, Kim Reh ${ }^{1}$, Scott Roberts ${ }^{1}$, Christophe Sotin ${ }^{1}$, Benjamin Weiss ${ }^{2}$, William Whitaker ${ }^{1}$, Members of JPL's A-Team ${ }^{1}$

\section{Endorsers:}

Patricia Beauchamp ${ }^{1}$, lan Cohen ${ }^{3}$, Athena Coustenis ${ }^{4}$, Shannon MacKenzie ${ }^{3}$, Olivier Mousis ${ }^{5}$, Linda Spilker ${ }^{1}$

1 JPL/Caltech, ${ }^{2} \mathrm{MIT},{ }^{3} \mathrm{APL} / \mathrm{JHU},{ }^{4}$ Paris Obs. at Moudon, ${ }^{5} \mathrm{Aix}-\mathrm{Marsielle}$ Univ. 


\section{Introduction}

Scientific exploration of the Uranus System-including Uranus, its moons, rings, and magnetosphere-is not limited to Flagship class missions. In past studies [1][2][3], typical payloads and subsystems from Flagship missions are shown to be resource hungry. When instruments with high mass and power requirements are used on New Frontiers (NF) and Discovery class missions in a top down manner, they often limit the payload allocation, and consequently the science returns. However, with advancements in miniaturization, spurred by the ongoing SmallSat revolution, we can approach mission designs from the bottom up and not from the top down. That is, we can scale up SmallSat-inspired science instruments, making them redundant and long-lived, thus getting sufficiently high performance from them, while benefiting from the resource savings. Similarly, subsystems designed for SmallSat missions could be adapted up to NF class. Other approaches, including additive manufacturing, combined with generative design, and computational analysis may also lead to significant resource savings. When optimized, these component technologies could pack more content and reduce resource needs, leading to higher science returns than those downscoped from Flagship class missions, or using heritage components from past NF missions. With this approach, we could now design even more capable high-performing missions with breakthrough science, under the NF cost cap. In this White Paper, we outline a framework that would address a set of breakthrough science goals, using SmallSat-inspired instruments, subsystems with reduced resource requirements, and customized concept-of-operations, all framed into notional NF mission designs by optimizing the available resources. Through these examples-based on interviews with subject matter experts and studies performed at JPL's Innovation Foundry-we provide evidence for the feasibility of potential mission concepts. In particular, here we make the case for including the Uranus System as one of the named NF exploration targets in the Decadal Survey. This would complement the proposed OPAG strategy [10], and would enable the community to propose a variety of highly capable missions, with science returns well above the current expectations for NF class missions. We also recommend that the Decadal committee request a Uranus mission study, similar to the other Planetary Mission Concept Studies (PMCS), as part of the upcoming Decadal process to validate Uranus as a NF target.

\section{Methodology and assumptions}

We have conducted interviews with subject matter experts (SMEs) with expertise in planetary science and space technology. We focused on emerging trends related to the developments of instruments, technologies, and novel processes initially conceived for earth science and planetary science SmallSat missions. Subsequently we carried out an A-Team study at JPL's Innovation Foundry to prioritize science objectives for potential NF class missions. Our starting point was a set of science goals, objectives and recommendations from past studies and reference documents, including the previous Decadal Survey [1], the Ice Giants Pre-decadal Survey Study [2], and NASA's Roadmap to Ocean Worlds [3]. We also looked at relevant Research and Technology Development (R\&TD) activities. Our goal was to reduce mass and power requirements, while maximizing the science return for an improved value proposition, compared to the current state of practice for NF missions. Through the A-Team study the team identified three 
suitable NF class compatible mission architectures. The study represents a semi-quantitative assessment on the feasibility and viability of these concepts, providing a piecewise description of the mission architecture elements, and their approximate performance metrics towards resource savings. For first-order trajectory and arrival mass calculations we have leveraged the work done for the lce Giants pre-Decadal study [2]. The assumptions were updated to reflect a generic NF class configuration for launch vehicle options in line with past AOs and ROSES PMCS Groundrules, and using propulsion systems in line with the target NF mission class. This representative, yet non-optimized trajectory calculation yielded a sufficiently high arrival mass, giving us confidence about the feasibility and viability of our approach.

\section{Representative New Frontiers class mission designs \\ Trajectory and delivered mass}

To demonstrate concept feasibility, key aspects (or key elements) include the amount of mass that can be delivered to the Uranus system and related cruise time, both of which bound component lifetimes. We assumed a 2035 launch date, consistent with the expected NF-6 solicitation. We considered an Earth-Mars gravity assist (GA) trajectory with an 11 year flight time to Uranus, based on launch vehicle performance identified in past NF AOs. (In later years we could use a VEEGA (Venus-Earth-Earth) trajectory by including Venus.) This is a reasonable flight time, as radioisotope power systems (RPS) are designed for a 17 year lifetime (including 3 years of ground storage). An 11 year cruise would allow for a 3 year tour at Uranus. This is not limiting, as recent pre-Decadal study Groundrules extended this lifetime to 20 years, if required. Table 1 shows key mission design parameters with an Atlas V 551 launch vehicle, which could deliver $\sim 1850 \mathrm{~kg}$ at arrival and $\sim 1080 \mathrm{~kg}$ after Uranus orbit insertion (UOI). On a Delta IV Heavy launch vehicle the mass after UOI would increase to $1900 \mathrm{~kg}$. (In comparison, the New Horizons and Juno spacecraft dry masses were $401 \mathrm{~kg}$ and 1593 kg, respectively.) To first-order, a Falcon Heavy (Expendable) would provide comparable or better performance than a Delta IV heavy launcher. An order-of-magnitude preliminary analysis from this same A-Team study shows that adding a MaSMi Hall Thruster with $300 \mathrm{~W}$ power to the spacecraft could gain some performance and increase the useful mass in orbit by about $100 \mathrm{~kg}$ and reduce the cruise time by a few months. With these first-order mass numbers, we can confidently make the case for the feasibility of at least three mission architectures, discussed next.

\section{Example NF class mission architectures}

After exploring the extensive mission trade space identified in the Ice Giants report [2], we have selected three representative architectures suitable for NF class missions. A multiple-element Uranus flyby mission with an atmospheric entry probe represented the simplest architecture that can provide breakthrough science with in situ exploration of Uranus. Trading the entry probe mass for propulsion, the second architecture is a

Table 1: Mission design parameters (notional)

\begin{tabular}{|c|c|}
\hline Launch date & 2035 \\
\hline Launch Vehicle & Atlas V 551 \\
\hline Launch Mass & $\sim 4000 \mathrm{~kg}$ \\
\hline Propulsion & Chemical \\
\hline Trajectory & Earth-Mars GA \\
\hline Deep Space Delta-V & $2.5 \mathrm{~km} / \mathrm{s}$ \\
\hline DSM Propellant Mass & $\sim 2150 \mathrm{~kg}$ \\
\hline Arrival Mass & $\sim 1850 \mathrm{~kg}$ \\
\hline UOI Delta-V & $1.2 \mathrm{~km} / \mathrm{s}$ \\
\hline UOI Propellant Mass & $\sim 500 \mathrm{~kg}$ \\
\hline Tank Mass & $\sim 270 \mathrm{~kg}$ \\
\hline Useful Mass post UOI & $\sim 1080 \mathrm{~kg}$ \\
\hline \multicolumn{2}{|c|}{$\begin{array}{l}\text { Arrival mass = Pre-Uranus Orbit Inser- } \\
\text { tion (UOI) S/C Mass }\end{array}$} \\
\hline \multicolumn{2}{|c|}{$\begin{array}{l}\text { Useful mass = Post UOI S/C Mass - } \\
\text { Prop Tank Mass - UOI Prop Mass }\end{array}$} \\
\hline
\end{tabular}


Uranus system orbiter, enabling the exploration of Uranus and a few of its satellites. The third architecture combines the benefits of an atmospheric entry probe and the orbiter. With the available mass at Uranus, and resource savings on systems and instruments, this architecture could also be supported.

Uranus flyby with an atmospheric entry probe: This architecture, at a minimum, would include a carrier spacecraft and an atmospheric entry probe. On approach to Uranus the carrier would release the probe for atmospheric entry, then perform a small trajectory correction maneuver for flyby. The $\sim 1850 \mathrm{~kg}$ arrival mass would provide significant margin to support this architecture. Leveraging instrument miniaturization and additive manufacturing, the entry probe could be as small as $\sim 175 \mathrm{~kg}$ (including aeroshell), significantly smaller than the historic $339 \mathrm{~kg}$ Galileo probe. Following atmospheric entry the probe would separate from the aeroshell and descend to a depth of $\sim 10$ bar in about an hour, performing in situ science investigations and relaying the data to the carrier spacecraft flying overhead. [4] The carrier spacecraft would safely pass through the rings, carry out remote science investigations of Uranus, its rings, and one or more of its satellites, with the measurements and payload to be defined in future optimized mission designs studies. Even a flyby mission will be able to obtain unique data on the Uranian rings, including the opportunity to look for changes since the Voyager 2 mission and to further examine the rings with much more sensitive instruments than those carried by Voyager. The main cost-reducing factors are: the smaller probe mass, and more compact instruments. This architecture represents the lowest cost option, but also the narrowest science return. The concept is analogous to the proposed (NF-4) Saturn Probe (SPRITE) mission. The concept could be enhanced by a CubeSat flying through the rings, as well as science instruments added to the primary carrier spacecraft for observations during the cruise phase.

Uranus System orbiter: Following an orbit capture near the polar region and a plane change maneuver at apoapsis to reduce inclination to $\sim 30$ degrees, the spacecraft would perform a multi-year orbital tour of the Uranus system to explore Uranus, a number of its satellites, and ring system (see also [9]). With an optimized trajectory, satellite flybys would afford multiple moderate-to-high resolution views of major satellites, and would characterize the Uranus system [8]. A close flyby at 50-100 km altitude could identify subsurface oceans by searching for signatures of magnetic induction. A flyby of Mab and the $\mu$-ring could provide insight into moon and ring formation. The post UOI useful mass is $\sim 1080 \mathrm{~kg}$ (see Table 1), and can be as high as $1950 \mathrm{~kg}$, assuming a larger launch vehicle and a MaSMi thruster. Feasibility of Uranus orbit tours have been evaluated for Flagship and SmallSat mission concepts in [2] and [5]. This NF concept is scaled between them. It would significantly increase the science return compared to a flyby mission, but would not include in situ exploration of Uranus. It is analogous to the Oceanus Titan orbiter (NF-4) and to ELSAH and ELF (also NF-4). A potential extra flight element could include a "Ride-along" CubeSat, deployed on approach to Uranus, to fly through the rings, offering a close-up view before expiring. This would be similar to the CubeSats planned for the DART and Hera missions to Didymos pair of NEAs. The main cost reducing factors are: the reduced mass and power for avionics. Enhancers are more compact instruments, allowing a larger diversity of measurements.

Uranus System orbiter with a Uranus atmospheric entry probe: Similar to the flyby mission, the spacecraft would release the probe about 30 days before atmospheric 
entry, retarget for a flyby, receive probe data during a flyover, perform an UOI maneuver, and carry out the system tour. As the $175 \mathrm{~kg}$ probe would be released before UOI, this would reduce the post $\mathrm{UOI}$ mass by $\sim 140 \mathrm{~kg}$, due to savings on propellant and tankage mass of the spacecraft. Depending on the launch configuration, this would result in a useful spacecraft mass in the range of $\sim 940$ to $\sim 1810 \mathrm{~kg}$. Leveraging resource savings from SmallSat inspired technologies (see Section 5), this would be sufficient to achieve the breakthrough science objectives shown in Table 2. This architecture provides the highest value proposition, combining the benefits of a Uranus tour with in situ measurements from the Uranus atmospheric entry probe. The concept is analogous to the VOX mission (NF-4). The main cost reducing factors are: the smaller probe mass, more compact instruments, reduced mass and power for avionics. Having the most mission elements among the three architectures, there is also a potential for international partnering to add instruments and enhance science.

\section{Breakthrough science}

The primary driver for selecting these concepts is breakthrough science. Through the A-team study we have identified a subset of science objectives from the Ice Giants Flagship study [2], that can be supported by these three architectures. A model payload and science priorities for Ice Giant entry probe missions are described in [4]. A tabulated summary of science objectives, observables, and instruments-as they map into the three notional mission architectures-is shown in Table 2.

\section{Instruments inspired by SmallSat developments}

The representative list of instruments outlined below are provided for illustration purposes only, and could be substituted with other similarly suitable instruments. In our strawman payload suite when possible, we highlighted SmallSat inspired instruments to replace larger heritage Flagship instruments. At other times we considered small (low mass and power) heritage instruments. The assumed payload suite for the spacecraft included the following ten instruments: an Advanced Pointing Imaging Camera (APIC, 6 kg, 4W); a Doppler Imager (DI, 10 kg, 10 W); Gravity Radio Science (GRS) in two-way mode using the UST-Lite Radio, while a USO or Chip Scale Atomic Clock could be used for occultation science or a probe DWE; an UV-Vis Spectrometer (UVS, 100 gram, $<1 \mathrm{~mW}$ per channel); a Langmuir probe (LANG, $1 \mathrm{~kg}, 100 \mathrm{~mW}$ ); a Magnetometer (MAG, $1.5 \mathrm{~kg}, 2 \mathrm{~W}$ ); a Polarimetric Camera (PCAM, $1.7 \mathrm{~kg}$ ); a Plasma Spectrometer (PS, 5.6 kg, 2.7 W); Radio Science (Radio/USO) (RS, using the UST-Lite Radio); and a Thermal IR Imager (TIR, $12 \mathrm{~kg}, 25 \mathrm{~W}$ ). The spacecraft payload mass adds up to less than $40 \mathrm{~kg}$ and the power is below $50 \mathrm{~W}$. For the suggested Ice Giants atmospheric probe instruments, in-depth information can be found in [4]. In our strawman probe payload suite we included the following instruments: an Atmospheric Structure Instrument, including Ortho-Para Hydrogen (ASI, $1.2 \mathrm{~kg}, 3.5 \mathrm{~W}$ ); Doppler Wind (Radio/USO) (DW, using the UST-Lite Radio and USO/CSAC); a Helium Abundance Detector (HAD, $1.4 \mathrm{~kg}, 0.9 \mathrm{~W}$ ); a Nephelometer (NEP, $1.1 \mathrm{~kg}, 2.4 \mathrm{~W}$ ); and a Quadrupole Ion Trap Mass Spectrometer (QITMS, $4 \mathrm{~kg}, 41 \mathrm{~W}$ ) [7]. The probe payload mass (w/o UST-Lite) adds up to be $<8 \mathrm{~kg}$ and the power is $<40 \mathrm{~W}$. All discussed instruments are at least at TRL-4, and will be matured to TRL-6 or higher by the targeted NF-6 opportunity. A program of accelerated life-testing would ensure their reliability for a deep space mission to the outer planets. Mapping of these instruments into science objectives are shown in Table 2. 
Table 2: Summary of science objectives, observables, instruments mapped into mission architectures

\begin{tabular}{|c|c|c|c|c|}
\hline \multirow[t]{2}{*}{ Objectives (O\#) } & \multirow{2}{*}{$\begin{array}{c}\text { Observables (Obs.\#) } \\
\text { (Only Breakthrough Level science } \\
\text { is included) }\end{array}$} & \multicolumn{3}{|c|}{ Example Mission Architectures } \\
\hline & & $\begin{array}{l}\text { Flyby + } \\
\text { Probe }\end{array}$ & Orbiter & $\begin{array}{l}\text { Orbiter + } \\
\text { Probe }\end{array}$ \\
\hline \multicolumn{5}{|c|}{ Planetary Interior, Bulk Composition, Atmosphere } \\
\hline \multirow{4}{*}{$\begin{array}{l}\text { O1: Uranus Interior Structure: } \\
\text { Constrain the structure and } \\
\text { characteristics of the planet's } \\
\text { interior, including layering, } \\
\text { locations of convective and } \\
\text { stable regions, internal } \\
\text { dynamics. }\end{array}$} & Obs.1: Gravity Field & & SC:RS & SC:RS \\
\hline & Obs.2: Magnetic Field & & $\begin{array}{l}\text { SC:MAG } \\
\text { SC:PS }\end{array}$ & $\begin{array}{l}\text { SC:MAG } \\
\text { SC:PS }\end{array}$ \\
\hline & $\begin{array}{l}\text { Obs.3: Planetary scale oscillations } \\
\text { (atmosphere, gravity field, ring structure) }\end{array}$ & & $\begin{array}{l}\text { SC:APIC } \\
\text { SC:DI }\end{array}$ & $\begin{array}{l}\text { SC:APIC } \\
\text { SC:DI }\end{array}$ \\
\hline & $\begin{array}{l}\text { Obs.5: Horizontal variation in properties } \\
\text { (surface or deep interior) }\end{array}$ & $\begin{array}{l}P: A S I \\
P: D W\end{array}$ & $\begin{array}{l}\text { SC:APIC } \\
\text { SC:UVS }\end{array}$ & $\begin{array}{l}\text { SC:APIC } \\
\text { SC:UVS } \\
\text { P:ASI } \\
\text { P:DW }\end{array}$ \\
\hline \multirow{3}{*}{$\begin{array}{l}\text { O2: Uranus bulk composition: } \\
\text { Determine the planet's bulk } \\
\text { composition, including } \\
\text { abundances and isotopic ratio } \\
\text { of } \mathrm{D} / \mathrm{H} \text {, noble gases and other } \\
\text { heavy elements. }\end{array}$} & $\begin{array}{l}\text { Obs.6: Noble gas abundances ( } \mathrm{Na}, \mathrm{Ne}, \mathrm{Ar} \\
\mathrm{Kr}, \mathrm{Xe}) \text { and } \mathrm{D} / \mathrm{H} \text {-ratios }\end{array}$ & P:QITMS & & P:QITMS \\
\hline & $\begin{array}{l}\text { Obs.7: Isotopic ratios of noble gases and } \\
\mathrm{H}, \mathrm{C}, \mathrm{N}, \mathrm{O}\end{array}$ & P:QITMS & & P:QITMS \\
\hline & Obs.8: Everything else in the atmosphere & P:QITMS & & P:QITMS \\
\hline \multirow{2}{*}{$\begin{array}{l}\text { O3: Measure the atmospher- } \\
\text { ic heat balance: Determine } \\
\text { horizontal distribution of atm. } \\
\text { thermal emission (reflected vs. } \\
\text { emitter IR radiation). }\end{array}$} & Obs.9: Bond albedo & SC:TIR & SC:TIR & SC:TIR \\
\hline & Obs.10: Emitted IR energy & SC:TIR & SC:TIR & SC:TIR \\
\hline $\begin{array}{l}\text { O4: Determine the 3-D circula- } \\
\text { tion of the troposphere. }\end{array}$ & $\begin{array}{l}\text { Obs.11: Repeated maps of cloud features } \\
\text { to track winds as a range of wavelengths } \\
\text { (for vertical resolution) }\end{array}$ & & $\begin{array}{l}\text { SC:APIC } \\
\text { SC:UVS }\end{array}$ & $\begin{array}{l}\text { SC:APIC } \\
\text { SC:UVS }\end{array}$ \\
\hline \multirow[t]{2}{*}{$\begin{array}{l}\text { O5: Determine the atmospheric } \\
\text { structure (temperature, composi- } \\
\text { tion, clouds). }\end{array}$} & $\begin{array}{l}\text { Obs.15: Vertical and horizontal resolution } \\
\text { of condensible species in the troposphere, } \\
\text { of hydrocarbon and He in the strato- } \\
\text { sphere, and temperature retrievals in both } \\
\text { stratosphere and troposphere }\end{array}$ & & SC:UVS & SC:UVS \\
\hline & Obs.16: In-situ measurements & $\begin{array}{l}\text { P:ASI } \\
\text { P:DW } \\
\text { P:HAD } \\
\text { P:NEP } \\
\text { P:QITMS }\end{array}$ & & $\begin{array}{l}\text { P:ASI } \\
\text { P:DW } \\
\text { P:HAD } \\
\text { P:NEP } \\
\text { P:QITMS }\end{array}$ \\
\hline \multicolumn{5}{|c|}{ Rings and Satellites } \\
\hline \multirow{2}{*}{$\begin{array}{l}\text { O6: Determine the interior struc- } \\
\text { ture of all large satellites (and as } \\
\text { many small ones as possible); } \\
\text { induced magnetic fields to } \\
\text { contain subsurface oceans. }\end{array}$} & Obs.17: Gravity field & & $\begin{array}{l}\text { SC:GRS } \\
\text { SC:RS }\end{array}$ & $\begin{array}{l}\text { SC:GRS } \\
\text { SC:RS }\end{array}$ \\
\hline & Obs.20: Global shape & & SC:APIC & SC:APIC \\
\hline \multirow[t]{3}{*}{$\begin{array}{l}\text { O7: Geologic Histories of } \\
\text { Satellites }\end{array}$} & Obs.24: Plumes and subsurface oceans & & $\begin{array}{l}\text { SC:APIC } \\
\text { SC:MAG } \\
\text { SC:PS }\end{array}$ & $\begin{array}{l}\text { SC:APIC } \\
\text { SC:MAG } \\
\text { SC:PS }\end{array}$ \\
\hline & Obs.25: Plume deposits & & $\begin{array}{l}\text { SC:APIC } \\
\text { SC:UVS } \\
\text { SC:TIR }\end{array}$ & $\begin{array}{l}\text { SC:APIC } \\
\text { SC:UVS } \\
\text { SC:TIR }\end{array}$ \\
\hline & $\begin{array}{l}\text { Obs.28: Composition of pickup ions in the } \\
\text { magnetosphere (originating from satellite } \\
\text { surfaces, exospheres, or plume activity) }\end{array}$ & & $\begin{array}{l}\text { SC:MAG } \\
\text { SC:PS }\end{array}$ & $\begin{array}{l}\text { SC:MAG } \\
\text { SC:PS }\end{array}$ \\
\hline
\end{tabular}




\begin{tabular}{|c|c|c|c|c|}
\hline \multirow[t]{2}{*}{ Objectives (O\#) } & \multirow{2}{*}{$\begin{array}{c}\text { Observables (Obs.\#) } \\
\text { (Only Breakthrough Level science } \\
\text { is included) }\end{array}$} & \multicolumn{3}{|c|}{ Example Mission Architectures } \\
\hline & & $\begin{array}{l}\text { Flyby + } \\
\text { Probe }\end{array}$ & Orbiter & $\begin{array}{l}\text { Orbiter + } \\
\text { Probe }\end{array}$ \\
\hline $\begin{array}{l}\text { O8: Get an inventory of small } \\
\text { moons including those within the } \\
\text { rings. }\end{array}$ & $\begin{array}{l}\text { Obs.35: Surface composition of small } \\
\text { moons; phase properties }\end{array}$ & & SC:UVS & SC:UVS \\
\hline $\begin{array}{l}\text { O10: Characterize the ring } \\
\text { structures and their temporal } \\
\text { variability. }\end{array}$ & $\begin{array}{l}\text { Obs.39: Fine-scale radial and azimuthal } \\
\text { structure and particle size constraints in } \\
\text { selected rings }\end{array}$ & & SC:PCAM & SC:PCAM \\
\hline \multirow[t]{2}{*}{$\begin{array}{l}\text { O11: Determine the shape and } \\
\text { surface geology of satellites. }\end{array}$} & $\begin{array}{l}\text { Obs.46: Local high-resolution surface } \\
\text { mapping and topology }\end{array}$ & & SC:APIC & SC:APIC \\
\hline & Obs.47: Plumes & & SC:UVS & SC:UVS \\
\hline \multicolumn{5}{|c|}{ Magnetosphere } \\
\hline $\begin{array}{l}\text { O12: Understand the basic } \\
\text { structure of the planet's } \\
\text { magnetosphere as well as the } \\
\text { structure and temporal evolution } \\
\text { of the dynamo. }\end{array}$ & $\begin{array}{l}\text { Obs.50: Magnetic field } \\
\text { (structure, variability, and oscillation) }\end{array}$ & & $\begin{array}{l}\text { SC:MAG } \\
\text { SC:PS }\end{array}$ & $\begin{array}{l}\text { SC:MAG } \\
\text { SC:PS }\end{array}$ \\
\hline \multirow{2}{*}{$\begin{array}{l}\text { O13: Measure plasma transport } \\
\text { throughout the magnetosphere, } \\
\text { from solar wind into the } \\
\text { ionosphere. }\end{array}$} & $\begin{array}{l}\text { Obs.54: Magnetic field } \\
\text { (structure, variability, and oscillation) }\end{array}$ & & SC:MAG & SC:MAG \\
\hline & Obs.55: Charged particles & & $\begin{array}{l}\text { SC:MAG } \\
\text { SC:PS } \\
\text { SC:LANG }\end{array}$ & $\begin{array}{l}\text { SC:MAG } \\
\text { SC:PS } \\
\text { SC:LANG }\end{array}$ \\
\hline \multirow{2}{*}{$\begin{array}{l}\text { O14: Determine how the } \\
\text { atmosphere and magnetosphere } \\
\text { couple and if the magnetosphere } \\
\text { significantly heats the } \\
\text { thermosphere. }\end{array}$} & $\begin{array}{l}\text { Obs.58: Magnetic field } \\
\text { (structure, variability, and oscillation) }\end{array}$ & & SC:MAG & SC:MAG \\
\hline & Obs.59: Charged particles & & $\begin{array}{l}\text { SC:LANG } \\
\text { SC:PS }\end{array}$ & $\begin{array}{l}\text { SC:LANG } \\
\text { SC:PS }\end{array}$ \\
\hline \multicolumn{5}{|c|}{$\begin{array}{l}\text { Example Spacecraft Instruments (SC): } \\
\text { SC:APIC - Advanced Pointing Imaging Camera; SC:DI - Doppler Imager (e.g., Mach-Zehnder Interferometer); } \\
\text { SC:GRS - Gravity Radio Science (Radio/USO); SC:UVS - UV-Vis Spectrometer; SC:LANG - Langmuir probe; } \\
\text { SC:MAG - Magnetometer; SC:PCAM - Polarimetric Camera (e.g., } 3 \text { or } 4 \text { EECAMs w/ polarizing filters); } \\
\text { SC:PS - Plasma Spectrometer; SC:RS - Radio Science (Radio/USO); SC:TIR - Thermal IR Imager }\end{array}$} \\
\hline \multicolumn{5}{|c|}{$\begin{array}{l}\text { Example Atmospheric Entry Probe Instruments (P): } \\
\text { P:ASI - Atmospheric Structure Instrument, including Ortho-Para Hydrogen; P:DW - Doppler Wind (Radio/USO); } \\
\text { P:HAD - Helium Abundance Detector; P:NEP -Nephelometer; P:QITMS - Quadrupole lon Trap Mass Spectrometer }\end{array}$} \\
\hline
\end{tabular}

\section{Enabling technologies inspired by SmallSat developments}

SmallSat-inspired flight system technologies can play a role in mission design to reduce resource (mass, power, Delta-V) needs. Technologies considered for this study included: Sabertooth electronics (SmallSat); telecom with UST-Lite (SmallSat); deployable mesh antennas (SmallSat); thermal control utilizing additive manufacturing (SmallSat); small electric propulsion with a MaSMi Hall thruster (SmallSat); power generation with a Radioisotope Power System, power storage with advanced battery technologies; concept of operations combined with autonomy; and advanced thermal protection systems [6].

\section{Conclusions and Recommendations for Future Studies}

In this White Paper we demonstrated the feasibility of a novel approach to NF class missions to the Uranus System, inspired by advancements in instruments and technologies originally developed for SmallSat missions. Our underlying A-Team study was an initial semi-quantitative and piecewise assessment of concept feasibility. We have 
shown that by carefully selecting breakthrough science objectives and reducing resource requirements through this approach, we have conceived a number of potential mission architectures with richer science returns than offered through a more traditional design framework. For example, when comparing the current approach to NF with a descoped Flagship concept in [2], the benefits are clear. On the spacecraft, the expected science return from ten SmallSat-inspired instruments within a $40 \mathrm{~kg}$ mass allocation would be higher than three heritage instruments fitting into a $50 \mathrm{~kg}$ allocation [2]. The six smaller instruments under $8 \mathrm{~kg}$ inside an atmospheric entry probe would be 4 times lighter than reported in [2] for a large probe. This would also shrink the volume and reduce the overall probe mass from $321 \mathrm{~kg}$ [2] to $175 \mathrm{~kg}$. The lower power needs for instruments and subsystems would allow for a single NextGen RTG, compared to five eMMRTGs in [2] on a Flagship mission.

In our study, we have identified three representative architectures: a) a flyby with probe; b) an orbiter; and c) an orbiter with probe. Our first order calculations indicate that we can deliver sufficient mass to the Uranus System for any of these architectures. Leveraging SmallSat developments for instruments and systems (when it makes sense), we could design robust NF class missions. For example, a mission launched in 2035 with an 11 year flight time would enable a minimum 3 year orbital tour of the Uranus system. With limited resources we could carry out breakthrough science investigations addressing Planetary Science Decadal Survey science objectives. The mass and power savings would accommodate a larger complement of instruments than concepts downscaled from a Flagship class payload suite. Even with telecom transmit power as low as $\sim 300 \mathrm{~W}$, combined with the UST-Lite radio and a $3 \mathrm{~m}$ antenna, the spacecraft could provide up to $\sim 1.5 \mathrm{kbps}$ downlink rate in X-band to a $34 \mathrm{~m}$ DSN dish, while a Ka-band link to a $70 \mathrm{~m}$ antenna could support $\sim 4 \mathrm{x}$ higher data rates. Future studies could consider an up to $5 \mathrm{~m}$ deployable antenna, and low-power GaN SSPAs instead of high-power TWTAs to increase data rates while reducing power requirements. Preliminary cost assessments through the A-Team study indicated that all three architectures would be able to accommodate the notional payload (with $50 \%$ margin at this study fidelity, and within the typical payload cost fraction on NF missions). Furthermore, the discussed architectures offer clear-cut opportunities for international partnerships (e.g. with ESA) to keep the cost of the mission to NASA at manageable levels. Partnerships could target instruments, the probe and spacecraft elements. Based on these findings, we recommend that the DS should consider pursuing a higher maturity study, such as a PMCS study, on a Uranus New Frontiers class mission. We also advocate for the inclusion of Uranus as one of the named New Frontiers targets.

\section{References}

[1] Squyres, S.W., et al. (2011). National Academies Press, Washington, D.C., p 410;

[2] JPL (2017). Ice Giants Pre-Decadal Study Final Report, Report Number JPL D-100520; [3] Hendrix, A.R., et al. (2019). Astrobiology, Vol.19, No.1, Mary Ann Liebert, Inc., DOI: 10.1089/ ast.2018.1955; [4] Atkinson, D.H., et al. (2020). Space Science Review (in print);

[5] Conversano, R. W., et al. (2019). 2019 IEEE Aerospace Conference, Big Sky, MT, USA, pp. 1-8, doi: 10.1109/AERO.2019.8741678; [6] Venkatapathy, E., et al. (2020). PSDS White Paper; [7] Simcic, J., et al. (2020). EGU General Assembly 2020, https://doi.org/10.5194/egusphereegu2020-2024; [8] Leonard, E., et al. (2020). PSDS White Paper; [9] Cohen, l, et al. (2020). PSDS White Paper. [10] Moore, J., et al. (2020) PSDS White Paper. 